\title{
ANALYTICAL VALIDATION OF CLOPIDOGREL IN HUMAN PLASMA THROUGH ULTRAHIGH- PERFORMANCE LIQUID CHROMATOGRAPHY-TANDEM MASS SPECTROMETRY
}

\author{
YAHDIANA HARAHAP*, INNET MAYSYARAH, HERMAN SURYADI
}

Department of Pharmacy, Faculty of Pharmacy, Universitas Indonesia, Depok, Indonesia. Email: yahdiana03@yahoo.com

Received: 21 April 2017, Revised and Accepted: 18 August 2017

ABSTRACT

Objective: This study developed a sensitive, selective, and valid method for analyzing clopidogrel in human plasma using liquid chromatographytandem mass spectrometry (LC-MS/MS).

Methods: The chromatography separation was performed on the waters ACQUITY UPLC Class BEH $\mathrm{C}_{18} 1.7 \mu \mathrm{m}(2.1 \times 100 \mathrm{~mm})$ column, consisting of $0.1 \%$ formic acid in water and $0.1 \%$ formic acid in acetonitrile (30-70) as the mobile phase, and an isocratic elution with a flow rate of $0.2 \mathrm{~mL} / \mathrm{minutes}$. The mass detection was performed using a Waters Xevo TQD equipped with positive electrospray ionization in the multiple reaction monitoring modes. The clopidogrel was detected at $\mathrm{m} / \mathrm{z} 322.086>212.097$ and irbesartan as an internal standard at $\mathrm{m} / \mathrm{z} 429.233>207.131$. The sample was prepared with protein precipitation method using acetonitrile, vortex mixed for 10 minutes, and centrifuged at 13,000 rpm for 20 minutes.

Results: This method showed a linear result at the concentration range of $0.2-10 \mathrm{ng} / \mathrm{ml}$ with $\mathrm{r} \geq 0.9997$.

Conclusions: The developed method provides sensitivity, linearity, precision, and accuracy and is suitable for analysis of clopidogrel in human plasma using LC-MS/MS.

Keywords: Clopidogrel, Irbesartan, Optimization, Liquid chromatography-tandem mass spectrometry, Validation.

(C) 2017 The Authors. Published by Innovare Academic Sciences Pvt Ltd. This is an open access article under the CC BY license (http://creativecommons. org/licenses/by/4. 0/) DOI: http://dx.doi.org/10.22159/ijap.2017.v9s1.79_86

\section{INTRODUCTION}

Clopidogrel is used for the secondary prevention of cerebral or myocardial infarction in patients who cannot tolerate acetylsalicylic acid or those who undergo a cerebral or myocardial infarction while taking acetylsalicylic acid [1]. The United States Food and Drug Administration has approved the drug to reduce the stroke level and the chance of myocardial infarction. Clopidogrel is a prodrug, with a slow onset, that has been found to be as effective as acetylsalicylic acid for secondary prevention in stroke. It provides a better toxicity profile, with a lower risk of causing thrombocytopenia and leucopenia, than other antiplatelet drugs, such as ticlopidine [2]

Clopidogrel is a platelet aggregation inhibitor that is systemically hydrolyzed into its inactive metabolite, carboxylic acid. The main clopidogrel concentration, or that which cannot be metabolized, has been found to be 2,000 times lower than the carboxylate acid metabolite. In addition, clopidogrel is metabolized into thiol, which is an active metabolite. The unstable chemical structure and low concentration are challenges in the analysis of clopidogrel in plasma [3-5]. Therefore, there is a need for a sensitive and selective method to measure the clopidogrel concentration in plasma, using liquid chromatographytandem mass spectrometry (LC-MS/MS).

In 2008, the guideline on the investigation of bioequivalence from the European Medicines Agency (EMA) stated that the measurement of the clopidogrel concentration in the plasma can be performed by measuring the inactive metabolite [6]. However, in 2010, it was suggested that a more accurate pharmacokinetic profile can be obtained by measuring the parent compound, not the inactive metabolite [7]. It was also suggested that special treatment was needed to prevent the conversion of the metabolite back into the parent drug (clopidogrel). This requires the use of low temperatures in the storage and extraction and refraining from the use of methanol during the analysis. This back-conversion could potentially occur when methanol is used as part of the extraction solvent, reconstitution solvent, chromatography mobile phase, or for the preparation of the calibrators, quality control (QC) solutions, and internal standards during the bioanalysis [3].

In 2007, a validation of the clopidogrel analytical method with liquidliquid extraction using diethyl ether was performed [8]. The lower limit of quantification (LLOQ) obtained in this study was $10 \mathrm{pg} / \mathrm{mL}$, with a maximum serum concentration $\left(\mathrm{C}_{\max }\right)$ of $1.7 \mathrm{ng} / \mathrm{ml}$, but this LLOQ still met the EMA recommendation, because it did not exceed a $\mathrm{C}_{\max }$ of $5 \%$. However, this study used methanol to produce the stock solution and dilution; therefore, it was possible that back-conversion occurred, biasing the results. In 2012, another study conducted a validation of the clopidogrel analytical method through protein precipitation, which was simpler and did not use methanol in the analysis [8]. However, the LLOQ obtained in that study was $250 \mathrm{pg} / \mathrm{ml}$, which was higher than the recommended limit.

In the current study, we performed an optimization of the plasma clopidogrel analysis method by modifying the published analysis method. The optimization performed was to change the internal standard to irbesartan and compare the results of the different sample preparation methods (liquid-liquid extraction and protein precipitation). Moreover, this study did not use methanol in the analysis to minimize bias in the clopidogrel concentration measurement results from the sample. The modified method was used to create a higher sensitivity and more valid result.

\section{METHODS}

Instrumentation

The ultrahigh-performance liquid chromatography (UHPLC)-MS/ MS (Xevo triple quadrupole (TQD) MS; Waters Corporation, Milford, Massachusetts, USA) consisted of a quaternary solvent manager (ACQUITY UPLC H-Class System; Waters Corporation, Milford, Massachusetts, USA), sample manager (ACQUITY UPLC H-Class System; Waters Corporation, Milford, Massachusetts, USA), nitrogen generator compressor (Peak Scientific, Milford, Massachusetts, USA), $2.1 \mathrm{~mm}$ $\times 100 \mathrm{~mm}$ C18-bonded silica column $(1.7 \mu \mathrm{m}$ ACQUITY UPLC BEH; 
Waters Corporation, Milford, Massachusetts, USA), mass analyzer (Xevo TQD Mass Spectrometer; Waters Corporation, Milford, Massachusetts, USA) with an ionization source (Z-Spray; Milford, Massachusetts, USA), data analyzer software (MassLynx Software; Milford, Massachusetts, USA), and computer (Lenovo, Beijing, China).

\section{Chemicals}

The clopidogrel hydrogen sulfate (99.7\%) was obtained from MSN Laboratories (Telangana, India), the irbesartan was obtained from the Zhejiang Huahai Pharmaceutical Co., Ltd., (Zhejiang, China), and the HPLC grade acetonitrile and formic acid were obtained from Merck (Darmstadt, Germany). All of the water used in this experiment was HPLC grade, prepared using a direct-Q 5 Water Purification System (Millipore, Watford, UK), and filtrated using $0.45 \mu \mathrm{m}$ membrane filters (Sartorius UK Ltd., Epsom, UK). The plasma was obtained from Indonesian Blood Transfusion Service and stored at $-20^{\circ} \mathrm{C}$ until use.

\section{LC-MS/MS method}

The chromatography consisted of an ACQUITY UPLC $C_{18}$ column $(1.7 \mu \mathrm{m}, 100 \times 2.1 \mathrm{~mm}$; Waters Corporation, Milford, Massachusetts, USA), using the isocratic elution method with $0.1 \%$ formic acid in water and $0.1 \%$ formic acid in acetonitrile (30:70) as the mobile phase, a flow rate of $0.2 \mathrm{ml} /$ minutes, and a column temperature of $35^{\circ} \mathrm{C}$. The mass detection was performed using the electrospray ionization positive mode of the multiple reaction monitoring types, with an $\mathrm{m} / \mathrm{z}$ (mass per charge ratio) value of $322.086>212.097$ for the clopidogrel (Fig. 1) and 429.233>207.131 for the irbesartan (Fig. 2), and a run time of 5 minutes. The tandem mass spectrometer settings are detailed in Table 1.

\section{Stock solutions, calibrators, and control solutions}

The clopidogrel stock solutions were prepared by dissolving an appropriate amount of clopidogrel hydrogen sulfate in acetonitrile to give a final free base concentration of $0.1 \mathrm{mg} / \mathrm{ml}$. The stock solutions were stored at $-20^{\circ} \mathrm{C}$ until use. The calibrators and control solutions were prepared by spiking stock solutions in human plasma. The concentrations of the clopidogrel hydrogen sulfate used to make the calibration curves were $200,500,1000,1500,5000,7500$, and $10,000 \mathrm{pg} / \mathrm{ml}$. The concentrations of the QC samples were $7.5 \mathrm{ng} / \mathrm{ml} \mathrm{QC}$ high, $5 \mathrm{ng} / \mathrm{ml} \mathrm{QC}$ medium, and $1 \mathrm{ng} / \mathrm{ml}$ QC low QCL.

\section{Preparation of the sample solution}

\section{Protein precipitation}

A $250 \mu \mathrm{L}$ of plasma containing clopidogrel with a concentration of $100 \mathrm{ng} / \mathrm{ml}$ was put in a microtube, and then, $20 \mu \mathrm{L}$ of irbesartan $(100 \mathrm{ng} / \mathrm{ml}$ concentration) was added. This sample was vortex mixed for 30 seconds. Next, $750 \mu \mathrm{l}$ of acetonitrile was added to precipitate the protein. This mixture was vortex mixed for 10 minutes and centrifuged for 20 minutes at $13,000 \mathrm{rpm}$. An aliquot from the centrifugation product was separated into other tube, and then, centrifuged again for 10 minutes at 3,000 rpm. The $300 \mu \mathrm{l}$ aliquot obtained was separated into clean vials to be analyzed through the LC-MS/MS system.

\section{Liquid-liquid extraction}

A $250 \mu \mathrm{l}$ of plasma containing clopidogrel with a concentration of $100 \mathrm{ng} / \mathrm{ml}$ was put in a microtube; then, $20 \mu \mathrm{l}$ of irbesartan (100 ng/ml concentration) was added. This sample was vortex mixed for 30 seconds. The liquid-liquid extraction was performed by adding organic solvent equivalent to 8 times the amount of the total plasma. This mixture was then vortex mixed for 2 minutes and centrifuged at 3,000 rpm for 15 minutes. Next, $1.5 \mathrm{ml}$ of the organic phase was moved to a test tube and evaporated until dry at $40^{\circ} \mathrm{C}$ using $\mathrm{N}_{2}$ gas for 20 minutes. The residue obtained was reconstituted with $100 \mu \mathrm{l}$ of the mobile phase $0.1 \%$ formic acid in water and $0.1 \%$ formic acid in acetonitrile, 50:50, v/v), then sonicated for 5 minutes, and vortex mixed for 1 minute. The reconstituted sample was moved into a microtube and centrifuged again for 10 minutes at 3,000 rpm. Then, $10 \mu \mathrm{l}$ of aliquot

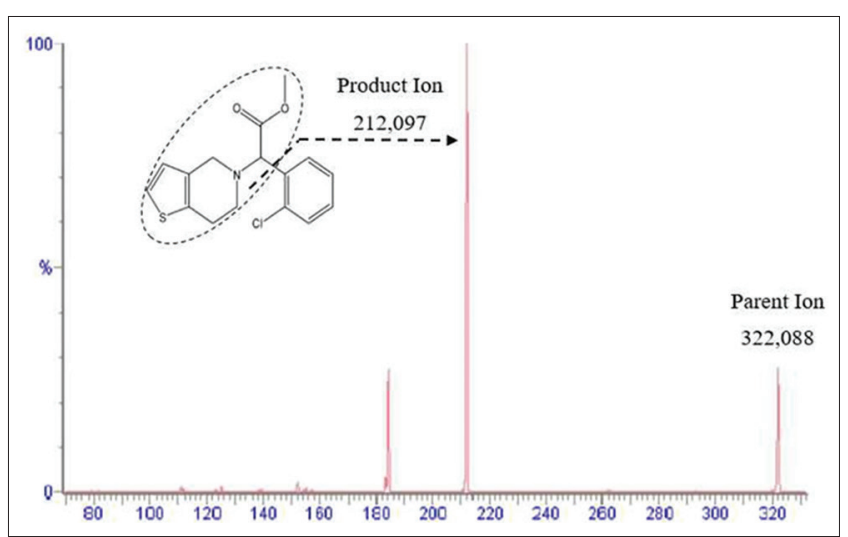

Fig. 1: Product ion mass spectra of clopidogrel

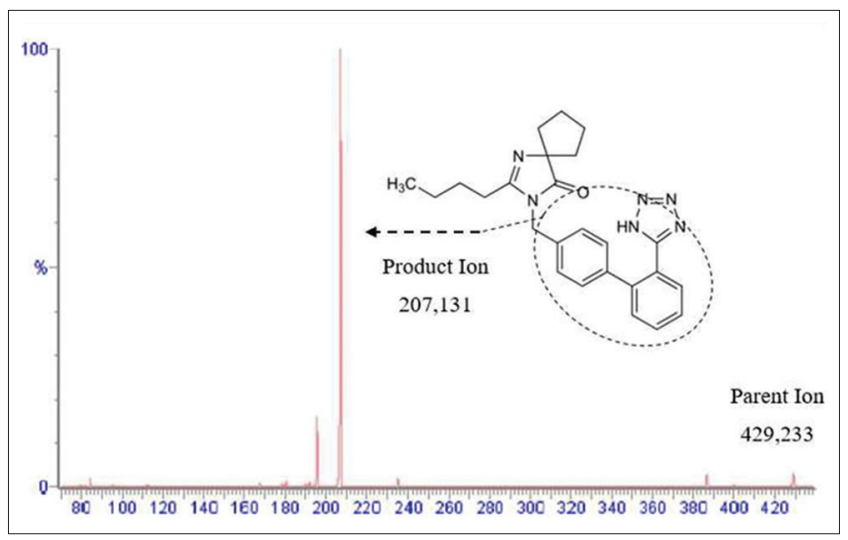

Fig. 2: Product ion mass spectra of irbesartan

was injected to the LC-MS/MS system. The organic solvents used in this method were ether and dichloromethane. The results obtained from the protein precipitation and liquid-liquid extractions were compared, the optimum extraction method was chosen, and the results were optimized again.

\section{Method validation}

After the optimization of the extraction sample, the validation of the analytical method was performed. The bioanalysis of the validation method parameters included the selectivity, carryover, LLOQ, linearity, accuracy and precision, recovery, dilution integrity, matrix effects, and stability. The analytical method validation was performed using control solutions and working solutions.

\section{RESULTS AND DISCUSSION}

\section{Plasma preparation}

The liquid-liquid extraction showed a higher response than the protein precipitation method although the contaminant area of the plasma blank was lower in the protein precipitation method. The results showed that the $200 \mathrm{pg} / \mathrm{ml}$ concentration in the liquid-liquid extraction using dichloromethane was 3,335 (as the analyte response), while the liquidliquid extraction using ether was 1,179, and the protein precipitation was 131. However, the protein precipitation method was used for the extraction in the final experiment because the liquid-liquid extraction required a longer time and produced a higher amount of contaminant, resulting in a more complicated validation method and a biased result. The analytical method using protein precipitation was found to be easier and faster and produced a lower amount of contamination. The protein precipitation method was then optimized. The optimum preparation method was found by adding $750 \mu \mathrm{l}$ of acetonitrile to the plasma sample, then vortex mixing it for 10 minutes and stirring it with centrifugation for 20 minutes. 


\section{LLOQ measurement}

According to the analysis performed by Karaźniewicz-Łada in 2012, the LLOQ obtained from the protein precipitation extraction method was $250 \mathrm{pg} / \mathrm{ml}$ [8]. In this study, the concentration used to obtain the LLOQ was $200 \mathrm{pg} / \mathrm{ml}$. The LLOQ obtained from the concentration of $200 \mathrm{pg} / \mathrm{ml}$ resulted in $14.8-18.57 \%$ as the relative error (\%RE) values and $1.35 \%$ as the relative standard deviation (\%RSD). According to the 2011 EMA Guideline on Bioanalytical Method Validation, the LLOQ value obtained should not exceed $5 \%$ of the $\mathrm{C}_{\max }$ value. The $\mathrm{C}_{\max }$ value of the $75 \mathrm{mg}$ clopidogrel tablet was $2.1 \mathrm{ng} / \mathrm{mL}$; therefore, the LLOQ should not exceed $105 \mathrm{pg} / \mathrm{mL}$. This method did not meet the requirement; however, the LLOQ obtained was lower than that in the study by Karaźniewicz-Ładaz [9]

\section{Calibration curve}

The calibration curve ranged from $200 \mathrm{pg} / \mathrm{ml}$ to $10,000 \mathrm{pg} / \mathrm{ml}$. The calibration curve included the plasma blank (plasma without analyte or internal standard), zero plasma (plasma with internal standard), and non-zero plasma (plasma with analyte and internal standard) at 7 concentrations $(200,500,1000,1500,5000,7500$, and $10,000 \mathrm{pg} / \mathrm{ml})$. The calibration curve showed a linear regression using the following formula: $y=0.0001+0.004 x$. The correlation value and $\% R E$ met the requirements of not more than $\pm 15 \%$ for the concentration (without the LLOQ) and not more than $\pm 20 \%$ for the LLOQ concentration. The average correlation coefficient was 0.9996 .

\section{Accuracy, precision, and recovery}

The accuracy was performed to determine the proximity of the measurement result to the true amount of clopidogrel, which was expressed through the \%RE. The precision was tested to determine the repeatability of the result obtained in this analysis, which was expressed through the \%RSD. The \%RE values obtained from the intraday accuracy test for the LLOQ concentration were 14.81-18.58\%, and they were $-13.65-9.24 \%$ from the other concentrations. For the intraday precision, the \%RSD value obtained was $1.36 \%$ for the LLOQ, $3.92 \%$ for the low concentration, $9.69 \%$ for the medium concentration, and $5.94 \%$ for the high concentration. For the interday accuracy test for the clopidogrel, the \%RE values obtained for the LLOQ concentration were $-14.00-18.58 \%$, and they were $-13.65-9.24 \%$ for the other concentrations. For the interday precision test, the \%RSD value obtained was $10.72 \%$ for the LLOQ 7.07 for the low concentration, $7.09 \%$ for the medium concentration, and $4.42 \%$ for the high concentration. These results showed that the analytical method used met the requirements for intra- and inter-day accuracy and precision (Table 2). The recovery test for this analytical method was performed relatively, with the use of low, medium, and high concentrations. The relative recovery values obtained from the clopidogrel in the low, medium, and high concentrations were 86.48-102.95\%, 86.25-103.6\%, and $93.6-102.55 \%$, respectively.

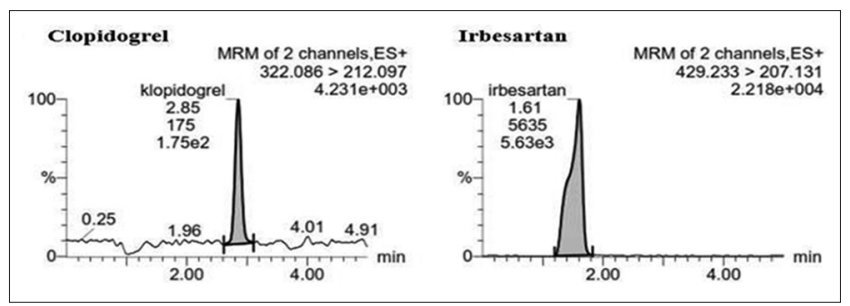

Fig. 3: Representative multiple reaction monitoring chromatograms of an extracted $200 \mathrm{pg} / \mathrm{mL}$ lower limit of quantification plasma sample

Table 1: Mass spectrometer settings for the analytical method

\begin{tabular}{|c|c|c|c|c|c|}
\hline Compound & Fragmentation ion $(\mathrm{m} / \mathrm{z})$ & Capillary voltage (kV) & Desolvation temperature $\left({ }^{\circ} \mathrm{C}\right)$ & Cone (V) & Collision (V) \\
\hline Clopidogrel & $322.086>212.097$ & 3.5 & 800 & 36 & 26 \\
\hline Irbesartan & $429.233>207.131$ & & & 38 & 24 \\
\hline
\end{tabular}

Table 2: Intra- and inter-day precision and accuracy

\begin{tabular}{|c|c|c|c|c|c|c|c|c|c|}
\hline \multirow[t]{2}{*}{ Concentration $(\mathrm{pg} / \mathrm{mL})$} & \multicolumn{3}{|l|}{ Day 1} & \multicolumn{3}{|l|}{ Day 2} & \multicolumn{3}{|l|}{ Day 3} \\
\hline & $\begin{array}{l}\text { Measured } \\
\text { value }(\mathrm{pg} / \mathrm{mL})\end{array}$ & $\% R E$ & $\%$ RSD & $\begin{array}{l}\text { Measured } \\
\text { value }(\mathrm{pg} / \mathrm{mL})\end{array}$ & $\%$ RE & $\%$ RSD & $\begin{array}{l}\text { Measured } \\
\text { value }(\mathrm{pg} / \mathrm{mL})\end{array}$ & $\% \mathrm{RE}$ & $\%$ RSD \\
\hline \multirow[t]{5}{*}{200 (LLOQ) } & 230.08 & 15.04 & \multirow[t]{5}{*}{1.35} & 178.99 & -10.50 & \multirow[t]{5}{*}{8.09} & 220.79 & 10.40 & \multirow[t]{5}{*}{7.13} \\
\hline & 234.48 & 17.23 & & 172.00 & -14.00 & & 192.30 & -3.85 & \\
\hline & 237.15 & 18.58 & & 203.32 & 1.66 & & 200.79 & 0.39 & \\
\hline & 232.03 & 16.01 & & 203.14 & 1.57 & & 225.18 & 12.59 & \\
\hline & 229.60 & 14.81 & & 177.03 & -11.48 & & 224.60 & 12.30 & \\
\hline \multicolumn{10}{|l|}{ \%RSD interday=10.72 } \\
\hline \multirow[t]{5}{*}{$1,000(Q C L)$} & 936.26 & -6.37 & \multirow[t]{5}{*}{3.91} & 864.77 & -13.52 & \multirow[t]{5}{*}{4.39} & 930.72 & -6.93 & \multirow[t]{5}{*}{5.74} \\
\hline & 979.20 & -2.08 & & 876.70 & -12.33 & & 1059.39 & 5.94 & \\
\hline & 1028.53 & 2.85 & & 881.20 & -11.88 & & 989.99 & -1.00 & \\
\hline & 1029.27 & 2.93 & & 887.47 & -11.25 & & 1076.16 & 7.62 & \\
\hline & 986.42 & -1.36 & & 963.35 & -3.66 & & 1006.12 & 0.61 & \\
\hline \multicolumn{10}{|l|}{$\%$ RSD interday=7.07 } \\
\hline \multirow[t]{5}{*}{5,000 (QCM) } & 4929.81 & -1.40 & \multirow[t]{5}{*}{9.69} & 5279.90 & 5.60 & \multirow[t]{5}{*}{3.09} & 5146.15 & 2.92 & \multirow[t]{5}{*}{4.10} \\
\hline & 5449.11 & 8.98 & & 5453.03 & 9.06 & & 4838.69 & -3.23 & \\
\hline & 4422.43 & -11.55 & & 5034.94 & 0.70 & & 5180.03 & 3.60 & \\
\hline & 4579.13 & -8.42 & & 5115.57 & 2.31 & & 5403.74 & 8.07 & \\
\hline & 4317.36 & -13.65 & & 5259.97 & 5.20 & & 5008.43 & 0.17 & \\
\hline \multicolumn{10}{|l|}{$\%$ RSD interday $=7.09$} \\
\hline \multirow[t]{5}{*}{ 7,500 (QCH) } & 733.41 & -2.21 & \multirow[t]{5}{*}{5.94} & 8189.70 & 9.20 & \multirow[t]{5}{*}{3.87} & 7559.99 & 0.80 & \multirow[t]{5}{*}{4.00} \\
\hline & 7077.48 & -5.63 & & 7503.51 & 0.05 & & 7991.97 & 6.56 & \\
\hline & 7969.32 & 6.26 & & 7691.52 & 2.55 & & 7984.06 & 6.45 & \\
\hline & 7651.44 & 2.02 & & 7443.02 & -0.76 & & 8057.02 & 7.43 & \\
\hline & 8192.68 & 9.24 & & 7596.15 & 1.28 & & 7359.58 & -1.87 & \\
\hline
\end{tabular}

LLOQ: Lower limit of quantification, QC: Quality control, QCL: Quality control low, QCM: Quality control medium, QCH: Quality control high, RSD: Relative standard deviation, RE: Relative error 


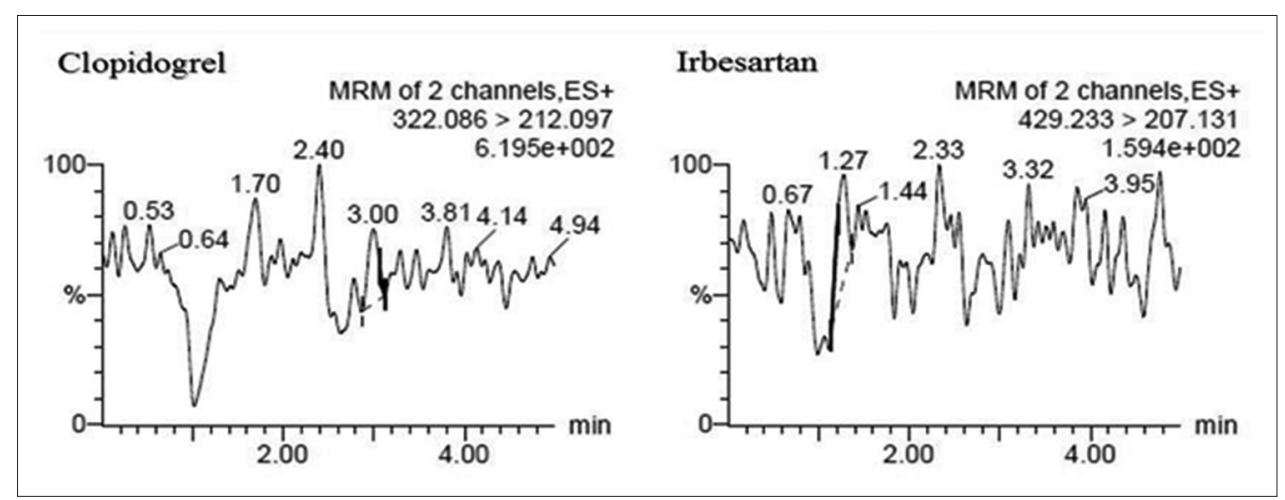

Fig. 4: Representative multiple reaction monitoring chromatograms of the plasma blank

\section{Selectivity test}

The selectivity test was performed to measure the ability of the analytical method to differentiate and quantitatively measure an analyte in a biological matrix. The selectivity was measured using the $\% \mathrm{RSD}$ and \%RE. According to the study results, the \%RSD of the clopidogrel was $4.63 \%$, with \%RE values of $5.35-18.70 \%$, which still met the requirements. In addition, the chromatogram from the plasma blank did not show any interference from the endogenous compounds in the plasma samples obtained from the six individual donors, thus meeting the selectivity requirements (Figs. 3 and 4).

\section{Carryover}

This study was performed to measure whether the residues of the analyte and internal standard were carried over to the plasma blank after the injection of the highest concentration (upper limit of quantitation or ULOQ). The carryover result from the clopidogrel retention time was not more than $12.76 \%$, with an average of $5.835 \%$. As the internal standard, the carryover result from the irbesartan retention time was not more than $0.828 \%$, with an average of $0.733 \%$.

\section{Dilution integrity}

This test was performed to assess the dilution process used for the analysis, which did not affect the accuracy and precision of the results. In this study, the \%RE values obtained from the intraday test for the $1: 2$ dilution were $0.03-4.37 \%$, with a $\%$ RSD of $1.86 \%$; for the $1: 4$ dilution, the $\%$ RE values were $-5.14-0.07 \%$, with a $\%$ RSD of $1.99 \%$. The $\%$ RE values obtained from the interday test for the one-half dilution were 7.008-0.03\%, with a \%RSD of $2.15 \%$; for the $1: 4$ dilution, the $\% \mathrm{RE}$ values obtained were $-6.95-7.81 \%$, with a $\%$ RSD of $3.78 \%$.

\section{Stability test}

The stability data showed that the clopidogrel and irbesartan were stable for at least 30 days in the acetonitrile stock solutions stored at $-20^{\circ} \mathrm{C}$, as concluded from the $\% \mathrm{RE}$ values $(-0.07 \%-1.34 \%)$. The results of the stability test of the analytes in the samples during storage for 24 hrs using the autosampler were within the \%RE range required (-5.9$1.12 \%$ ). The stability of the analytes in the plasma samples during storage at room temperature for $24 \mathrm{hrs}$ was expressed by the \%RE values $(-8.66-9.24 \%)$. The \%RE values obtained from the long-term stability study were $-3.16-9.24 \%$. This proved that the analytes were stable in the plasma samples during the 10 days, they were stored in the freezer at $-20^{\circ} \mathrm{C}$. Moreover, the analytes were proven to be stable in the plasma samples after three freeze-thaw cycles, as demonstrated by the \%RE values obtained (-8.79-9.24\%).

\section{Matrix effect}

According to the experiment performed, the matrix factor value obtained for the QCL was $101.376 \%$, meaning that at this concentration, there was ions enhancement, although not significantly, the value was near $100 \%$ [10-13]. The matrix factor value obtained in the high concentration was $85.053 \%$, meaning that there was ions suppression $[14,15]$. The internal standard matrix factor value was
99.463\%, meaning that there was a slight decrease in the ions. However, the percentage of RSD values of the matrix factor for the analyte and internal standard still met the criterion $(<15 \%)$.

\section{CONCLUSION}

The analytical method developed in this research can be used to analyze the clopidogrel concentration in the plasma. It met the validation requirements according to 2011 EMA Guideline on Bioanalytical Method Validation with regard to the selectivity, accuracy, precision, carryover, linearity, matrix effect, dilution integrity, and stability.

\section{REFERENCES}

1. Dipiro JT, Talbert RL, Yee GC, Matzke GR, Wells BG, Posey LM. Pharmacotherapy A Pathophysiologic Approach. $3^{\text {rd }}$ ed. New York: The McGraw-Hill Companies. Inc.; 2008.

2. Brunton LL, Chabner B, Knollmann BC, editors. Goodman \& Gilman's the Pharmacological Basis of Therapeutics. New York: McGraw-Hill Medical; 2011

3. Robinson A, Hillis J, Neal C, Leary AC. The validation of a bio analytical method for the determination of clopidogrel in human plasma. J Chromatogr B Analyt Technol Biomed Life Sci 2007;848(2):344-54.

4. Nirogi RV, Kandikere VN, Shukla M, Mudigonda K, Maurya S, Boosi R. Quantification of clopidogrel in human plasma by sensitive liquid chromatography/tandem mass spectrometry. Rapid Commun Mass Spectrom 2006;20(11):1695-700.

5. Shin BS, Yoo SD. Determination of clopidogrel in human plasma by liquid chromatography/tandem mass spectrometry: Application to a clinical pharmacokinetic study. Biomed Chromatogr 2007;21(9):883-9.

6. European Medicines Agency. CHMP efficacy working party therapeutic subgroup on pharmacokinetics (EWP-PK). Guideline on the Investigation of Bioequivalence (Draft). London: An Agency of the European Union; 2008

7. European Medicines Agency. CHMP efficacy working party therapeutic subgroup on pharmacokinetics (EWP-PK). Guideline on the Investigation of Bioequivalence. London: An Agency of the European Union; 2010.

8. Food and Drug Administration. Guidance for Industry: Bioanalytical Method Validation. United States of America: Department of Health and Human Services; 2013.

9. Karazniewicz-Lada M, Danielak D, Tezyk A, Zaba C, Tuffal G, Glówka F. HPLC-MS/MS method for the simultaneous determination of clopidogrel, its carboxylic acid metabolite and derivatized isomers of thiol metabolite in clinical samples. J Chromatogr B Analyt Technol Biomed Life Sci 2012;911:105-2.

10. Kruve A, Leito I. Comparison of different methods aiming to account for/overcome matrix effects in LC/ESI/MS on the example of pesticide analyses. Anal Methods 2013;5:3035-44.

11. Henriques ST, Castanho MA. Environmental factors that enhance the action of the cell penetrating peptide pep-1 a spectroscopic study using lipidic vesicles. Biochim Biophys Acta 2005;1669(2):75-86.

12. Marangon E, Posocco B, Mazzega E, Toffoli G. Development and validation of a high-performance liquid chromatography-tandem mass spectrometry method for the simultaneous determination of irinotecan and its main metabolites in human plasma and its application in a clinical pharmacokinetic study. PLoS One 2015;10(2):e0118194. 
13. Ciaffoni L, Hancock G, Harrison JJ, van Helden JP, Langley CE, Peverall R, et al. Demonstration of a mid-infrared cavity enhanced absorption spectrometer for breath acetone detection. Anal Chem 2013;85(2):846-50.

14. Chico J, Holthoon F, Zuidema T. Ion suppression study for tetracyclines in feed. Chromatogr Res Int 2012;2012:135854.

15. Panuwet P, Hunter RE Jr, D'Souza PE, Chen X, Radford SA, Cohen JR, et al. Biological matrix effects in quantitative tandem mass spectrometry-based analytical methods: Advancing biomonitoring. Crit Rev Anal Chem 2016;46(2):93-105. 